\title{
MECHANISM OF DRUG ACTIVITY
}

" $\mathrm{H}^{\circ}$ OW DO DRUGS ACT ?" was the subject of an address delivered by Sir Walter LangdonBrown to an evening meeting of the Pharmaceutical Society on February 13. He classified the principal ways in which drugs act thus : (1) they increase or diminish the effects of stimuli reaching the cell from without ; (2) they modify the chemical changes occurring within the cell itself ; (3) they may themselves be so altered in chemical constitution by the cell as to be capable of fresh activity, yet with diminished toxicity. He illustrated each of these methods by examples, some of the best illustrations of the first group from hormones, of the second from vitamins, and of the third from chemotherapy.

It was little realized at the beginning of this century that a new era had dawned when Langley showed that the effect of adrenaline on any part was the same as if the sympathetic nerve to it had been stimulated; it merely seemed an interesting example of a chemical substance imitating a nervous stimulus. But it was much more important than that; although adrenaline has no effect on a structure which has never received a sympathetic innervation, Elliott found that cutting off that innervation did not abolish the effect of adrenaline on a structure which had once possessed it. On the contrary, its effect was actually increased. For this reason both Langley and Elliott independently put forward the theory of a receptive substance beyond the nerve ending, on which the drug acted. Sympathetic stimulation has been found to produce adrenaline at the nerve endings; this is in addition to the adrenaline always stored up in the medulla of the adrenal gland which can be drawn upon as an emergency ration when there is a sudden demand for widespread action of the sympathetic for purposes of defence. Other illustrations were given showing how the normal transmission of the nervous stimulus is effected and the ways in which it may be interfered with or assisted by certain drugs.

Sir Walter next gave some examples of the way in which drugs may act by modifying the chemical changes within the cell itself; he started by discussing some of the activities of thyroid extract, the quickening effect of which on metabolism has been described as the draught to a fire.

Other observations on drugs and oxidation processes were followed by extensive references to vitamin $\mathrm{C}$ (ascorbic acid), which is now so widely used as a drug. As a strong reducing agent, it acts by balancing oxidation and reduction changes in the cell. Much study, said Sir Walter, has been recently directed to vague ill-health, short of that necessary to induce scurvy, due to lack of vitamin C. $\mathrm{He}$ gave an example which showed clearly that a specific case of vague ill-health was due to dietetic deficiency, and the material ascorbic acid was ready to hand to re-establish healthy oxidation and reduction changes within the cell.

Chemotherapy illustrates the third group, the alteration of a drug by the cell so that it assumes fresh activity yet with diminished toxicity. Sir Walter said that the treatment of any malady with a chemical agent of known composition may be included, strictly speaking, in the term chemotherapy, although it is almost universally limited to the treatment of parasitic diseases by chemical disinfection or control of the causative agent without producing marked toxic effect on its patient. The specific effects of drugs such as emetine in amœbic dysentery and arsphenamine in syphilis depends upon their chemical interactions with some constituent of the living cell.

\section{MILK AND NUTRITION}

\begin{abstract}
A FULL account of a large-scale trial of the effects of giving various. milk supplements to children at school is given in the final report of the Milk Nutrition Committee ("Milk and Nutrition". Part 4. National Institute for Research in Dairying, Shinfield, Reading. $2 s$. post paid). The researches of the Committee have been undertaken to compare the nutritive values of raw and of pasteurized milk. In the present report, results are given of tests upon school children of the growth and health-promoting properties of supplements of $\frac{1}{3}$ or $\frac{2}{8}$ pint of milkamounts the same as those which figure in the Milkin-Schools Scheme of the Ministry of Health.

Some eight thousand children from five different areas were divided at random into four groups, to receive, over one year, a daily ration at school of (1) biscuits ; (2) $\frac{1}{3}$ pint of pasteurized milk; (3) $\frac{2}{3}$ pint of pasteurized milk; and (4) $\frac{2}{3}$ pint of raw milk. The children were periodically examined, measurements being made of their physique together with assessments of their state of nutrition, intellectual ability, and other features such as posture and complexion.
\end{abstract}

The general trend of the figures obtained, set out in a number of tables, shows that the children given milk supplements increased in height, chest-circumference, and strength of pull to a greater extent than those receiving biscuits, and also improved more in their general state of nutrition and in their teachers' assessment of their ability. In addition, those on the larger milk supplement usually showed an improvement above those on the smaller, while there was no consistent difference between those on similar supplements of raw and of pasteurized milk. The advan. tages accruing to the milk-drinkers compared with the biscuit-eaters were small, though uniform and significant, amounting to less than $\frac{1}{10} \mathrm{in}$. in height and $\frac{1}{4}-1 \mathrm{lb}$. in weight over the whole year during which the experiment was in progress. There was, unfortunately, no means of control over the home diet, and it is therefore possible that some given biscuits may have received additional milk at home, while milk-drinkers may have had extra biscuits.

A summary of the previously reported results of laboratory experiments on animals and feeding trials on calves is also given in this report. 